Belfer, M. L. \& Nurcombe, B. (2007) The epidemiology and burden of child and adolescent mental disorder. In The Mental Health of Children and Adolescents: An Area of Global Neglect (eds H. Remschmidt et al), pp. 27-42. John Wiley.

Belfer, M. L. \& Saxena, S. (2006) WHO child atlas project. Lancet, 367, 551-552.

Belfer, M. L., Remschmidt, H., Nurcombe, B., et al (2007) A global programme for child and adolescent mental health: a challenge in the new millennium. In The Mental Health of Children and Adolescents: An Area of Global Neglect (eds H. Remschmidt et al), pp. 1-11. John Wiley.

Grimes, K. E. \& Mullin, B. (2007) MHSPY: a children's health initiative for maintaining at risk youth in the community. Journal of Behavioral Health Services and Research, 34, 349-351.

Kessler, R. C., Chiu, W. T., Demler, O., et al (2005) Prevalence, severity, and comorbidity of 12-month DSM-IV disorders in the National Comorbidity Survey Replication. Archives of General Psychiatry, 62, 617-627.

Kim, W. J., American Academy of Child and Adolescent Psychiatry Task Force on Workforce Needs (2003) Child and adolescent psychiatry workforce: a critical shortage and national challenge. Academic Psychiatry, 27, 277-282

Levav, I., Jacobson, L., Tsiantis, J., et al (2004) Psychiatric services and training for children and adolescents in Europe: results of a country survey. European Child and Adolescent Psychiatry, 13, 395-401.

Murray, C. J. L. \& Lopez, A. D. (eds) (1996) The Global Burden of Disease. WHO.

Shatkin, J. P. \& Belfer, M. L. (2004) The global absence of mental child and adolescent mental health policy. Child and Adolescent Mental Health, 13, 395-401.

US Department of Health and Human Services (1999) Mental Health: A Report of the Surgeon General. US Department of Health and Human Services, Substance Abuse and Mental Health Services Administration, Center for Mental Health Services, National Institute of Mental Health National Institutes of Health.

WHO (2005) Atlas. Child and Adolescent Mental Health Resources. Global Concerns: Implications for the Future. See http://www.who.int/mental health/resources/Child_ado_atlas.pdf (last accessed August 2008).

\title{
Helping each other help children - worldwide research networks in child and adolescent mental health
}

\section{Stefan Ehrlich MD ${ }^{1}$ and Paul L. Plener MD²}

${ }^{1}$ Charité - Universitätsmedizin Berlin, Campus Virchow-Klinikum, Klinik für Psychiatrie, Psychosomatik und Psychotherapie des Kindesund Jugendalters, Augustenburger Platz 1, 13353 Berlin, Germany, email stefan.ehrlich@charite.de ${ }^{2}$ Department of Child and Adolescent Psychiatry and Psychotherapy, University of Ulm, Germany

$$
T_{\text {he }}^{\text {he }}
$$
he International Congress of the International Association of Child and Adolescent Psychiatry and Allied Professions (IACAPAP) takes place every other year. It is an opportunity for specialists from around the world to meet, exchange ideas and plan new projects. Since 2006, the Donald J. Cohen (DJC) Travel Fellowship has been an integral part of the Congress. It aims to foster the professional development of 'emerging leaders' in child and adolescent mental health (Adler et al, 2007).

At first glance, child and adolescent psychiatrists from highincome countries would be expected to have very different interests, and very different resources, from those from lowincome countries. Many young German child and adolescent psychiatrists, for example, do biological research using multichannel electroencephalography (EEG), magnetic resonance imaging (MRI), and genetic or cell biology assays. Those from low-income countries might be more interested in such things as the epidemiology of certain disorders in their region, the prevalence of particular conditions, such as child abuse, or the efficacy of community-based mental health programmes.

In Germany, the profession of child and adolescent psychiatry is rather young but well established, the treatment is covered by health insurance, advanced technological tools are accessible, and the medical research infrastructure is complex enough to support some highly specialised projects. In a low-income country there may be only a handful of child and adolescent psychiatrists nationally, the field is often not held in high esteem either by the public or by government, and funding and legislative support for child mental health are correspondingly weak. Health systems generally suffer from low funding and are focused on essential medical needs. Technology such as MRI devices is seldom available. Public health and clinical care take priority over basic research.

When child and adolescent psychiatrists from higher- and lower-income countries meet at a scientific conference, as we and others have under the auspices of the DJC Fellowship, the obvious question therefore is 'Can we help each other?' Which is to say, 'How can we help each other help children?' While forming personal and professional relationships is a good first step, the next is to consider carefully the opportunities for cooperation, and the obstacles.

\section{Tools of research}

If we think not about the specific substance of our research but rather about the tools we use, we see that researchers in higher- and lower-income countries face some similar challenges. Questions arise out of our daily clinical work. We must reframe those into more precise research questions, and devise an adequate research design. This requires access to the existing research literature, as well as resources such as reports from the World Health Organization (WHO). The relatively new journal Child and Adolescent Psychiatry and Mental Health offers free access to peer-reviewed, high-quality, worldwide information on all topics relevant to child and adolescent mental health (Fegert \& Vitiello, 2007). Web forums such as Medscape offer free access to some scientific journals 
and congress reports (http://www.medscape.com/welcome/ journals). In addition for scientists in low- and middle-income countries, the Journal of the American Academy of Child and Adolescent Psychiatry (JAACAP; http://www.jaacap.com) is now free.

We need to find good assessment tools, learn the methods and conduct the study. This requires that researchers understand validity, reliability and specificity, and also consider cultural appropriateness and cost-effectiveness. Some questionnaires are available free of charge. The library website of the University of Adelaide gives a detailed list of all psychiatric rating scales and diagnostic aids available online (http://www. adelaide.edu.au/library/guide/med/menthealth/scales.html).

Young researchers face financial constraints in both higherand lower-income countries, and these constraints oblige us all to acquire expertise in raising funds, and especially in writing grant applications. Last but not least, we have to analyse and interpret the data, and present our conclusions to the research community. Generating publishable research demands in-depth knowledge of higher-level statistics, and many child and adolescent psychiatrists lack such knowledge. Researchers who are not native-speakers of English may face the added obstacle of language, and so struggle both with writing articles and with choosing an appropriate journal to submit their articles to. These are all areas where skills and information can be usefully shared between child and adolescent psychiatrists from any part of the world.

A group of German biological researchers has formed an organisation called Young Investigators in Biological Child and Adolescent Psychiatry (YIBcap), as a means of encouraging such sharing. Although our research priorities are not the same, our knowledge of research tools and our experience in creating the 'social capital' (Shortt, 2004) of a research network are things we feel can be useful to researchers in lower-income nations. The skills of doing research, and of organising researchers into productive work teams, are not, in general, capital intensive or unique to biological research. Here, we present a brief history of our creation of YIBcap, and invite suggestions for further cooperation.

\section{Origins and purpose of YIBcap}

In 2005 we founded YIBcap with the goal of intensifying collaboration between all professions conducting biological research in child and adolescent psychiatry, and to increase both the quality and the efficiency of our research (Ehrlich \& Stegemann, 2007). Currently the group comprises 40 members from more than 10 different German university hospitals and different specialties - physicians, psychologists, biologists and nutritionists. All members communicate via web-based group software and our own homepage (http:// www.yibcap.de). We share new clinical and scientific knowledge, get quick advice on open questions (e.g. statistical matters) and collaborate on scientific projects. In addition, we rely on an expert panel of ten internationally renowned senior advisors - all senior faculty members in child and adolescent or adult psychiatry - who help young researchers with their methodological knowledge, writing skills, fund-raising techniques and contacts. Eventually, some of our senior faculty members will go beyond advice and instruction and engage in a trusting and caring mentor-mentee relationship (Martin,
2005). In the context of existing scientific congresses, we organise meetings where experts give workshops on research methods such as statistical multivariate analysis, gene linkage analysis, neurophysiology or diffusion tensor imaging.

\section{Present state and future challenges}

The network has had many successes in its first 3 years of existence. We have contributed to the translation and adaptation of questionnaires regarding self-harm, to a study of diagnostic issues in attention-deficit hyperactivity disorder, to the genotyping of patients with eating disorders, to the sharing of neuronal cell lines and to the transfer of EEG methodology. We were able to hold our own symposia at the IACAPAP conferences in 2006 and 2008, the 2007 conference of the European Society for Child and Adolescent Psychiatry (ESCAP) and have received official recognition and support from the German Association of Child and Adolescent Psychiatry and Psychotherapy. Currently, our first collaborative multicentre study on substance misuse is about to start.

Despite these achievements, we find that there are still many challenges. Funding for travel is hard to find. Mailing lists need to be moderated and protected to prevent misuse. Maintaining a website is labour intensive, as is organising meetings. One has to be cautious not to dissipate one's energies in administrative work.

Belonging to a rather small specialty within medicine, we feel that there is a great need for child and adolescent psychiatrists around the world to get to know each other, stay in touch, discuss recent advances in clinical care and research, as well as help each other with resources, methodology and contacts. E-communication and web logs are an efficient and affordable way to make use of this form of social capital. Web-based group software (e.g. Google groups, Yahoo groups) is free, and offers the distribution of emails to all group members, archiving of messages, file sharing, and polls. We also invite interested researchers to join YIBcap as guest members. We are especially interested in fostering dialogue with researchers in low- and middle-income countries.

Young researchers benefit in any context if they agree to share their knowledge and cooperate on research tasks. Time-efficient and cost-efficient means to communicate as a group are available through the internet. In order to benefit from external resources and to foster the seriousness of such networks, a board of senior researchers as advisors is highly recommended. In the midst of all our specialised research - the tracing of a specific receptor, the function of a subtle brain structure or gene - we should not forget that our primary goal is to serve the needs of children and adolescents, and to improve the mental health of the general population. Dialogue between child and adolescent psychiatrists from all over the world reminds us of this most important aim of our work, whether in biological research, epidemiology or community-based psychiatry.

\section{Acknowledgements}

We thank Nicolas Jefferson-Lenskyj, MA, from the University of Queensland, Australia, for help with the manuscript preparation. Both authors 
are founding members of YIBcap and former D. J. Cohen Fellows, but have no financial or other conflicts of interest that might bias their work.

\section{References}

Adler, R., Martin, A., Park, C., et al (2007) Mentoring young researchers: can the Donald I Cohen Fellowships model be applicable and useful to Australasian psychiatry? Australasian Psychiatry, 15, 232-236.
Ehrlich, S. \& Stegemann, T. (2007) [Young Investigators in Biological child and adolescent psychiatry (YIBcap) - insights after one year of networking.] Zeitschrift für Kinder- und Jugendpsychiatrie und Psychotherapie, 35, 59-63.

Fegert, J. M. \& Vitiello, B. (2007) Peer-reviewed, high quality, worldwide information on all topics relevant to child and adolescent mental health. Child Adolescent Psychiatry and Mental Health, 1, 1.

Martin, A. (2005) Ignition sequence: on mentorship. Journal of the American Academy of Child and Adolescent Psychiatry, 44, 1225-1229.

Shortt, S. E. (2004) Making sense of social capital, health and policy. Health Policy, 70, 11-22.

\title{
Child and adolescent mental health services in Pakistan: current situation, future directions and possible solutions
}

\author{
Faria Khan, ${ }^{1}$ R. K. Shehzad ${ }^{2}$ and Haroon R. Chaudhry ${ }^{3}$
}

${ }^{1}$ Child and Adolescent Services for Early Intervention, Lancashirecare NHS Trust, Lancashire, UK 2Department of Paediatrics, Clonmel General Hospital, Clonmel, Ireland ${ }^{3}$ Department of Psychiatry, Fatima Jinnah Medical College, Lahore, Pakistan

W orldwide, mental disorders are on the increase (Gadit, 2007) and an estimated $10-20 \%$ of children have one or more mental or behavioural problems (Park, 2002). There is an urgent and serious need to pay attention to the mental health needs of children in low- and middle-income countries (Rahman et al, 2000). The initial survey for the World Health Organization's Atlas project (Sherer, 2002) showed that $41 \%$ of countries surveyed had no mental health policy and $28 \%$ had no separate budget for mental health.

In Pakistan, with a population of 169 million, the allocation to adult mental health is hardly $1 \%$ of the annual health budget, and there is no specific allocation for children and adolescents. The provision of child and adolescent mental health services is very fragmented nationally.

This paper highlights the status of child and adolescent psychiatry services in Pakistan and makes some suggestions on how to develop them within the available resources.

\section{Current situation}

The current situation in Pakistan is that there is no formal referral pathway to psychiatric services for children. Children with mental and behavioural problems present to general practitioners in the community or to psychiatric out-patient departments, where they are seen by general adult psychiatrists, most of whom have little if any formal training in child psychiatry. However, it would not be improper to hypothesise that children reach these services after attending spiritual and faith healers.

The more common referrals involve neuropsychiatric and neurodevelopmental disorders, including behavioural sequelae of epilepsy and brain injury, pervasive developmental disorders, attention-deficit hyperactivity disorder, Tourette syndrome, early-onset psychosis, other psychoses, psychosomatic/dissociative disorders, eating disorders, depression, anxiety and obsessive-compulsive disorders.

If children require admission, they stay on general adult psychiatric wards with adults who are acutely mentally unwell. The staff have very little formal training in managing children. Hence, the burden falls on the parents and carers to look after and manage them, leading to further anxiety and distress, especially if a parent has to take time off work.

\section{Future directions and possible solutions}

Developing paediatric-psychiatric liaison services

In Pakistan, in order to make use of scarce resources and still provide an appropriate in-patient setting, a suitable model could be for admissions to be to the paediatric ward, but with full support from the psychiatric team. Each adult psychiatry department could set up a paediatric liaison facility. Where the child is acutely disturbed and is difficult to manage in the paediatric ward, there could be a designated area on the psychiatric ward, preferably away from adult patients.

Lack of communication among existing paediatric and psychiatric specialties needs to be addressed through integration. One way to establish services would be to hold joint departmental meetings once a month, to which ward nurses, psychologists and local general practitioners should also be invited, to increase their awareness of psychiatric disorders in children. Attendance at paediatric ward rounds and joint teaching sessions, journal clubs, case presentations and so on would allow a clearer understanding of the issues faced by all involved. 